\title{
Effects of therapeutic horse riding on gait cycle parameters and some aspects of behavior of children with autism
}

\author{
H Steiner, Zs Kertesz \\ Department of Control Engineering and Information Technology, University of Technology and Economics, \\ Budapest, Hungary
}

Received: September 17, 2014

Accepted after revision: February 26, 2015

\begin{abstract}
We studied effects of therapeutic riding on the development of children with autism. Experiments in walking is appropriate for assessing the coordination of movement and for following the changes. We found that therapeutic riding should be considered as a new form of rehabilitation. Twenty-six pupils (12 boys and 14 girls) of a special needs school participated in therapeutic riding. We analyzed walking twice during a school-term: full body analyses each time before and after one-month therapy. The research included a non-riding control group. All together 104 analyses were performed. We measured mental skills using Pedagogical Analysis and Curriculum (PAC) test consisting of four parts being communication, self care, motor skills and socialization. The Gait Cycle Analysis consists of the time-series analysis, the analysis of part of the gait cycle and the measurement of joint angles in each plane. We found significant differences between before and after the therapy in the length of the gait cycle that became more stable in the sagital plane and concluded that our results proved that horse therapy may be successfully used as an additional therapy for children with autism, and it may be a form of rehabilitation in cases when other therapies are not successful.
\end{abstract}

Keywords: pedagogical analysis and curriculum, gait, horse therapy, gait cycles, APAS

Health care undergoes substantial change in Europe that manifests in the appearance of new scientific methods and results, and in the renaissance of alternative medicine. The change was resuscitated by chronic diseases because they require long-term medical attendance; hospitalization and nursing. This situation made doctors and therapists to look for new alternative and gentle therapies. Horse therapy is proved to be one of the new and alternative therapies applied also in Hungary.

Horse therapy is a special therapy applied individually or in groups. It comprises different special methods such as Remedial Riding and Vaulting that were originally used by therapists working with autistic children.

There are other groups of patients who could benefit from horse therapy by improving their disturbed motor functions, overdue movements, poor balance, coordination, posture and behavior. Primary field of application of such therapy is the improvement of the gait mechanism.

\footnotetext{
Corresponding author: Henriette Steiner

Department of Control Engineering and Information Technology

University of Technology and Economics, Budapest, Hungary

Phone: (+36 1) 463-2699; E-mail: henriette@iit.bme.hu
} 


\section{The normal gait}

The human gait is a highly complex, most often performed part of the locomotion movement, therefore, it is difficult to describe precisely. The gait is based on the control and the integrated functioning of the central nervous system, and on the complex interplay of the skeletal and the muscular systems. Stages of the gait cycle can be identified from the $20^{\text {th }}-22^{\text {nd }}$ weeks of fetal life to the $2^{\text {nd }}-3^{\text {rd }}$ month of infancy (19). At this age, only some elements of the gait can be observed, and it does not represent real walking because of the missing gravity components and the balance reaction (19). The skills of gait appear in 6-8-month of age once again but this time, under gravity conditions (19). Infants are able to perform individual gaits at the age of 12-18 months but they need 6-7 more years (!) for development of complete, rhythmic and plastic, individual gaits.

\section{What is autism?}

Autism is a qualitative developmental disorder of social and cognitive communication skills that can result in lifelong disability. It can be a severe impairment accompanied by additional damages that is often compensated to a certain degree but very rarely satisfactorily. Those who are severly impacted require lifelong assistance while mild cases need support to varying degree. Contemporary literature defines various forms of autism as a uniform syndrome and calls it 'autism spectrum disorder' or 'pervasive developmental impairments' $(25,26)$.

Autism spectrum disorder (ASD) consists of a range of complex neurodevelopmental disorders, characterized by social impairments, communication difficulties, and restricted, repetitive and stereotyped patterns of behavior. The most severe form of ASD is commonly referred to as autism or classic ASD, while Asperger syndrome, childhood disintegrative disorder and pervasive developmental disorder not otherwise specified (usually referred to as PDD-NOS) are milder forms of the disorder along the spectrum (17). Although ASD occurs in all ethnic and socioeconomic groups and affects every age group, it varies significantly in character and severity. It is inferred that 1 out of 88 children of age 8 will have ASD (Centers for Disease Control and Prevention: Morbidity and Mortality Weekly Report, March 30, 2012). Males are four times more likely to be effected than are females (17).

Autism is proved to be strongly genetically determined. Evidence is brought by the study of autisms stressing that the disorder occurs 50 times more frequently $-2.7 \%$ - among siblings of children with autism than without $(17,25,26)$.

Autism occurs in $2.7 \%$ of siblings where at least one child is already diagnosed with the disorder $(17,25,26)$. This is a 50 times higher incidence than if there was no autism case previously in the family. Autism can be present at all intellectual levels. Due to various accompanying damages the sydrom can be very diverse depending on the severity of the autism, intellectual and other abilities, impairments, and on the child's personality. The insidence that was initially considered to be $0.0002-0.0004 \%(25,26)$ is currently estimated to be $0.5 \%$ in the entire population $(25,26)$, and it shows further growing tendency as inferred by some authors $(25,26)$. Autism is present directly or indirectly in $1-1.5 \%$ of the population when considering all family members. Autism was described and defined as spectrum disorder only in the 1990s (27) leaving not enough time for the society to adequately arrange servicing of patients with autism unlike patients with other type of disabilities such as Asperger. At the same time, professional care for children with ASD developed considerably in the last twenty years. 
What is horse therapy?

Horse therapy is the conscious, planned and controlled application of the horse and the riding for prevention and curing damage, improving and educating children and adults with different or normal developmental profile. Horse riding as therapy and as parasport aims to improve the quality of life of those whose health and development is at risk.

Horse therapy can also be defined as individual or group engagement based on medical, educational or psychological indications. The therapy makes use of the benefit of the proximity of horses and engagement with them. It aims to cure, maintain and improve the condition of the person whose status of injury is assessed previously. There are several types of horse therapy used depending on who the patients are and what the goals to be achieved are in the therapy. The diagnoses and the therapeutic goals determine the type of horse therapy is needed.

One type of horse therapy is the "special need educational horse riding and horse gymnastics therapy". It is an individual or group activity managed by a specifically trained special need expert. Stride, trot and gallop can be applied together with the elements of horse gymnastics, and different tools and games can be involved depending on the purpose and the goals set. Due to its complex effects, this type of therapy is most successful with intellectually impaired children, children with learning difficulties, autism, hyperactivity, vision, auditory, and behavioral impairment. Besides horse riding the therapy consists of gymnastics on horse back and caring for the horse. Riding can be administered by leading the horse on lunge or independently.

The UK, Switzerland, Austria are leading countries in horse therapy $(5,6,12)$. They have several decades of experience, and have proved and validated the application of the therapy in rehabilitation. Horse therapy is not administered in a therapeutic but in a field setting, therefore, it effects patients indirectly and more naturally adding value to its effectiveness. The different types of horse therapy cannot be separated from each other. Differences in type and severity of injury, in individual skills, in age and goals of therapy will result in differences in duration and focus on the applied methods.

Horse therapy is a complex method in prevention, improvement and curing symptoms of impairment primarily deriving from autism. It exerts its multidisciplinary effects on the tone of the muscles by regulating malfunctions. Horse therapy is beneficial for improving sensation, motor functions, body scheme, balance, coordination, and the control of the head and trunk movement $(5,6,7,9)$. Horse therapy may improve attention and cognition, broaden experience, grow self-confidence and improve selfexpression and independence $(5,6,7,9)$. While in contact with the horse the patient gets motivated as a sign of emotional development and experiences being in the flow. Establishing and keeping contact with the horse, the therapists and the peers improve social life. As a consequence of the therapy, communication and interaction skills improve together with emotional and will power cognitive functions.

Horse therapy and the riding-hall environment provides an excellent opportunity for the integration of people with autism into the social world of sports. The complexity of the riding positions play important role in improving the condition of people with other types of disabilities than autism. Horse therapy reduces handicap resulting and compensates for disability; it improves psychological functions such as sensation, perception, memory, attention and thinking $(5,6,7,9)$. The therapy is used to improve coordination of motor functions, to correct mal movements, establish adequate movements, reduce incorrect 
postures, improve balance and rhythm. Furthermore, horse therapy serves to help sensory integration, to improve awareness of the body, space and time. All these processes effect personality development and the capability to get around the world.

It can be concluded, that the complex application of the elements of horse therapy and riding in particular improve overall neurological and social functions of the participants. In Hungary, horse therapy has been applied since 1997, but there is no comprehensive study conducted on its effectiveness. Horse therapy is not yet included in the therapy list to be financed by the Hungarian Social Security.

\section{Materials and Methods}

\section{Work hypothesis}

Our aim was to investigate horse therapy from a medical point of view and explain why and how it works. We decided to use full Body Model analysis, because the most important issue was which displacements of body points (joints) and segments will be changed. When conducting our experiment we did not know yet what parameters will change significantly as a result of the horse therapy. Full body analyses were performed but constraints of the magnitude of this study prevent us to detail them here.

Our work hypothesis is that if horse therapy effects coordination of movements and provides a correct "motion template" for the muscles and the nervous system (the same way as during walking), it will exert an effect on walking as well.

We have examined the gait mechanism using special gait analysis before and one month after horse therapy performing altogether 104 gait analyses.

Walking requires coordinated interplay of many muscles, virtually of the whole body. Execution of these complex movements requires not only appropriate development of the muscular and the skeletal systems but also adequate control of movements.

\section{Criteria of investigation}

There was one and the same therapist and horse taking part in the experiment.

The 30-minute therapy sessions included riding in a saddle type "Western" in a walking rhytm while the horse was led. In addition to the therapist there was one person in each session leading the horse, and two assistants helping on both sides.

Elements of the session:

1. Warming up exercise of stretching on horseback while the horse was not moving (looking backwards, stroking horse's ear, horse's rump, etc.)

2. The same as in 1 but in walking
a) along the long side of the wall
b) in the entire riding hall
c) in one half of the hall
d) in a big circle
e) in a small circle
f) in a snake pattern

All 30-minute sessions were successfully completed by all the children.

There were no records taken on the improvement of quality of horse riding since the purpose of the therapy was not to teach participants to ride on horseback. During the sessions 
the members of the control group were travelling together with the therapy group to the riding hall. The control group did not receive horse therapy. Participants of the experiment were randomized.

Using the "BNO" code system (3) for defining the severity of the autism participants were classified as F84.0 - infentile autism and F71 - mentally retarded.

The physical activity of the participants was assed by a school physician and the groups participating in the experiment were created based on this assessment. The groups could be compared with each other. During designing the experiment, the Helsinki declaration was used as a guideline $(3,19)$. The experiment gained the necessary, authentic ethical approval.

Subjects were suffering autism and they were 10-13 years old. We examined 30 children, but four of them left the group because of hospitalization.

We created two groups of children:

1. horse therapy group of 13 children ( 6 boys, 7 girls)

2. control group of 13 children ( 6 boys, 7 girls)

We examined altogether 26 children (12 boys and 14 girls). In each group children were trained in special riding for 30 minutes a week.

\section{Therapeutic methods}

The investigated population was divided into two groups. In the sample group children participated in horse therapy for 30 minutes a week, and also received pedagogical sessions of education. The measurements were performed before the therapy, one month after the therapy followed by a control period of three months without any horse therapy. After a repeated one month of horse therapy we once again measured the participants. The control group had special pedagogical sessions for autistic children for one hour a day. We measured this group as follows:

1. before starting therapy

2. one month after therapy

3. after three-month break (without therapy)

4. after one month of horse therapy in case of the participants and physical therapy in case of control group.

\section{Gait analysis}

The gait analyzer equipment we used was the Ariel Performance Analysis System (APAS), a video based computer assisted system. The manufacturer, the Ariel Dynamics Inc. was founded in 1968 with the mission to produce computer based, biomechanical analysis tools in preparation for the Mexico City Olympic Games.

\section{Conformation of our APAS}

APAS consists of a heavy duty PC and four digital camcorders (60 Hz, PAL), the communication was made by Canopus A/D converter. The software we used to control the cameras requires a setting of $60 \mathrm{~Hz}$ to ensure sampling in every $0.02 \mathrm{~s}$.

We used four video cameras (type Sony) from four different views. Sampling frequency was 50 frames/second (sampling rate 0.02 second) with shutter speed of $1 / 250$ second. We processed the data by the APAS video analyzer system, recorded the gaits with four camcorders from four views (front, rear and two sides). Another heavy duty PC was used for special statistical analysis (T-probe, Paired T-probe, Mann-Whitney and ANOVA). 


\section{Pedagogical Analysis and Curriculum (PAC-test)}

The special test for mentally retarded individuals $(18,19)$, consists of the following parts:

- Communication (language, numbers, subtraction, paper-using)

- Self-care (dressing, washing, moving for transport, feeding)

- Motor skills (growth motor function skills, manual function)

- Socialization (housework, games)

Each section consists of several items; each item is worth one point. We analyzed each section: counted all items, and added up all points. The motor skill items strengthened or weakened each other according to the APAS biomechanical parameters.

\section{Results}

Calibration was performed before each measurement. A calibration cube marked at the 8 vertices was used to calibrate the system. The cube sets three coordinates of movement in sagittal, vertical and horizontal plane, alike Descartes' coordination system.

X-axis: sagittal plane

Y-axis: vertical plane

Z-axis: horizontal plane

The fixed point synchronizes column and row coordinates in every frame (this is the absolute zero point). After the measurement conditions were set and recorded the parallelepiped was removed so as not to bother the children in moving. The two bold black marks indicate a $200 \mathrm{~cm}$ long section in which the two gait cycles were analyzed.

In order to establish a body model, for the gait kinematic and kinetic analysis, a number of markers are attached on specific locations of various body parts. Markers are tracked automatically by the optoelectronic system to be represented as points in 3D space. After automatic tracking and 3D conversion, each marker has its own positional information/data in GCS (General Coordinate System). The configuration of specific locations of markers is called marker set. A good marker set shall meet several conditions.

\section{The body model}

We used a body model to follow the movements of several points of the body. On processing the data we applied a modified form of Dempster's body model that consists of 18 points and several connecting them $(1,8,10,11,15-20,22)$. The $19^{\text {th }}$ point is the center of mass of the body. Dempster's model was modified the following way. We defined the landmarks, segments, and interconnections of the model. For the construction of the model we conducted anthropometric measurements. The global and local anthropometric data of every child in the sample were taken into consideration (segment lengths, relative body masses, radiuses of gyration). Height and body weight were measured and the partial centers of mass of the body segments were calculated $(1,8,10,11,15-20,22)$. The final model was constructed after using these data. This method allowed us to follow the movements of the selected points of the body in three dimensions. We made smoothing (noise filtering) through quintic spline algorithm built in the APAS (1).

The body model and its structure are protected by the patent No. P 1000395 and is not the subject of this article. For testing the hypothesis of this experiment the changes of the position of the ankles measured at the surface point of the malleolus medialis et facies anterior et tuberculum laterale was sufficient to measure. We have used full body model to collect data for later analyses and publication. Three markers per ankle were used to measure position 
change. The change of the center of gravity was part of the analyses. Although center of gravity provides a lot of information about stability, our interest was focused on the changes behind the stability at a certain moment. In case of each participant we recorded 30 full gait cycles and we calculated the means of them.

\section{Statistical analysis}

The basis for the statistical analysis was the displacement of markers. The data were exported to Excel and after to SPSS 19 (a statistical analyzer program) we compared the differences between values of parameters of selected groups (length of gait cycle). The equality of standard deviation in the statistical population was checked by F-probe $(14,18)$.

We chose to analyze displacement of ankles, because it could help to define many parameters of the gait cycle $(2,9,11,14-17,20)$. We calculated the periodic local minimums and maximums of measured displacement function and amplitudes (differences of maximums and minimums). Time was calculated between the minimums and maximums to investigate the "constructions of gait cycle" $(11,14-17,20)$. Biomechanical research converts gait cycle into values: the distance of a heel-strike to other heel strike of the same foot $(2,11,14-17$, 20). These data were converted to real time with $0.02 \mathrm{~s}$ being the test period. Right and left sides were analyzed separately $(17,20)$. Fundamental statistical parameters were investigated: means, variances, minimums, maximums), and differences. Similarities in datasets were controlled with T-probe, paired T probe, Chi-squares, Mann-Whitney test, ANOVA) (14, $20,22)(p<0.05)$. Data of the gait cycle was counted as they follow:

\section{Sagital plane.}

Minimums indicate heel strike of the foot.

Maximums indicate toe-off of the foot.

\section{Vertical plane.}

Minimums indicate heel strike of the foot.

Maximums indicate highest point of the swing phase.

\section{Horizontal plane.}

Minimums indicate elongation of the foot to right side.

Maximums indicate elongation of the foot to left side.

The center line of the gait and the calibration cube is $+40 \mathrm{~cm}$.

\section{Results of analysis of the gait cycle in the sagittal plane}

The length of the gait cycle was measured from heel strike to other heel strike on the same side. The parameters are: distance $(\mathrm{cm})$ time $(\mathrm{s})$ and ratio of phases. One cycle is $100 \%$, swing phase ( $40 \%$ of stance phase) is $60 \%(14)$.

\section{Discussion}

The movement consists of phases made up of gait cycles. In normal gait there is a gradient in swing phase, in sagittal plane, and there is no gradient in stance phase (19). Periodicity of movement is produced by gait cycle: local maximums of the gait mean the maximum of gait cycle on the same side in vertical plane. In horizontal plane the periodicity is made up of the translocation of the weight to the other side. In this case the asymmetry of the two sides is typical; one of the sides, usually the right one is weaker. When analyzing the sagittal plane 
we measured changes in full gait cycle time between heel strike to heel strike on the same side. Figures 1 and 2 shows changes on each side analyzed separately while the length of the right side increases significantly. Similar change takes place on the other side as shown in Figure $1(p<0.05)$ representing larger gait cycles and better balance. The same is measured in case of taking the time from toe top to toe top in the riding group while there are no changes in the non-riding group.

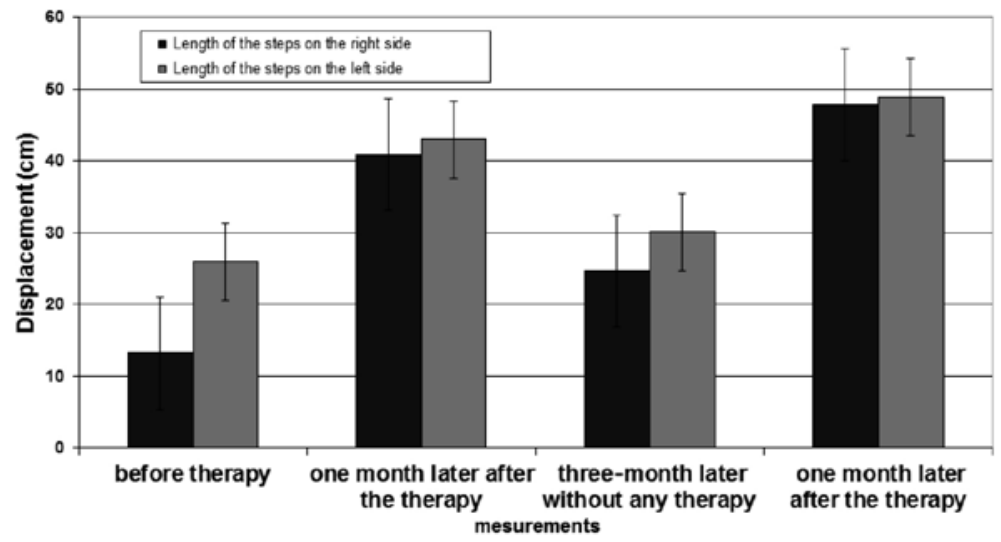

Fig. 1. Length of the gait cycle in the riding group (right and left side)

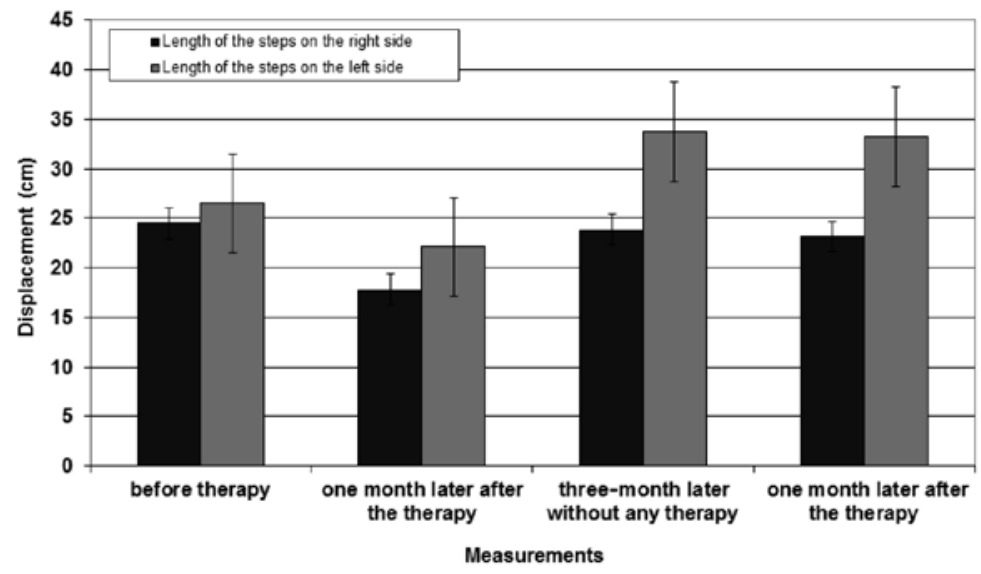

Fig. 2. Length of the gait cycle in non-riding group (right and left side)

The question was raised why asymmetry was observed between two sides in autism before therapy. In the study of Annett (1) the theory on the right shift of gene is described inferring that a typical rightward asymmetry may be a pervasive feature of functional brain organization in ASD affecting sensorimotor as well as higher cognitive functions (20). It is possible that this unusual pattern of asymmetry underlies some of the severe language deficits commonly found in children with autism, particularly in those with speech impairments (21). In case of autism, tensor skewness is greater on the right side and fractional anisotropy is decreased on the left side (22). 
In the horse therapy group indicators improved significantly on each side characterized by better coordination and orientation, and resulting in more effective walking in kinetic and kinematic way. The improvement is confirmed by the increase of the gait cycle from $13 \mathrm{~cm}$ to $50 \mathrm{~cm}$ after the therapy was completed in case of 73 percent of the participants.

In the control group length of the gait cycle on the right side was significantly ( $p<$ 0.005) decreased (Fig. 2). Data were collected by measurements in the following order and sequence:

1. before starting therapy

2. one month after therapy

3. three-month break - It means without any therapy (each groups)

4. after one month of horse therapy in case of the participants and physical therapy in case of control group.

There were significant differences between the group receiving horse therapy and between the control group at the beginning of the experiment. According to medical investigations, there was no significant difference between members of the two groups in terms of mobility status before the therapy. Significant differences could be observed from the data collected after the therapy. Since autism does have diverse manifestations it is unlikely to be able to create homogeneity of groups. When we took the mean of all 30-gait cycles we arrived at somewhat smaller difference than if we took the mean of the second 10gait cycles. Since the movement became most natural in the middle part of the gait cycles we decided to stick with the second 10-gait cycles for analyses. Because walking is an individual and dynamic form of movement, while walking from and towards the wall the length of gait cycles may increase or shorten, respectively.

The control group received physical therapy but no horse therapy. The parameters of the gait cycle slightly improved on the left side and slightly worsened on the right side resulting in an increased asymmetry. This result is against the goal of the therapy to create symmetry in movement. The phenomenon can be explained by several factors:

1. Physical therapy is not the right form of rehabilitation for children with autism.

2. Physical therapy can be a right form of rehabilitation but it should be different from the currently applied exercise elements.

3. The cooperation between the physical therapist and the child treated was not sufficient.

In order to decide which factor of the above three caused the phenomenon, it would be required to include a second control group not receiving any therapy at all. This situation would raise ethical concerns because we cannot threaten the development of someone by not providing any therapy to compensate for his/her injury.

Education takes many forms and has critical and important goals. Due to the development of inclusive practices and community involvement, people with intellectual disabilities and their families have been encouraged to live normal lives away from institutions. To do this effectively, individuals need a wide range of skills that frequently have not been learned during the normal school system. A number of challenging issues arise. These challenges may be best observed within the development of the approach to the quality of life of people with intellectual impairments. For example, one major characteristic of the approach to the quality of life is variability: people change over time and differ from each other. In education, it is extremely important to recognize this variability. The psychological, social and adaptive skills are very important in the process of cognitive and social development. In the first half of the $20^{\text {th }}$ century the attempts at social education improved, and by the $2^{\text {nd }}$ half of that 
century gained greater momentum (Gunzburg 1968). In our experiment, we have assessed communication skills (language, numbers), usage of papers, self-care (washing, wearing, traffic, eating), adaptive skills/socialization (housework, games) before and after horse therapy. Each sample group performed different exercises. When the patient gained the ability to do a certain exercise, helshe received one credit in that category. The credits were summed up and displayed on a Venn diagram for easy interpretation by the parents, therapists and physicians. The riding and non-riding group had the same pedagogical program (same therapist, and same exercises). The skills of the riding group are significantly better concerning all parameters $(p<0.000)$, in each item-groups. There was no change in parameters in the non-riding group.

We have also performed the PAC test that measures quite a few parameters of certain movements in addition to the Groth Motor Funcion Skills, but it cannot be compared to our biomechanical movement analyses. PAC measures development in pedagogical terms but its parameters change very often with those of the biomechanical ones in case of people who are severly disabled in their mobility and Down syndrome. This is not the case with autism.

These results support the hypothesis that horse therapy is a complex therapy and is suitable to improve condition in case of children with autism. It is useful to achieve better gait cycle and orientation and to improve mental skills. During the survey (nearly half a year) the following parameters were changed:

- length of the gait cycle increased meaning more stability in the sagittal plane and

- mental parameters were better in the riding group.

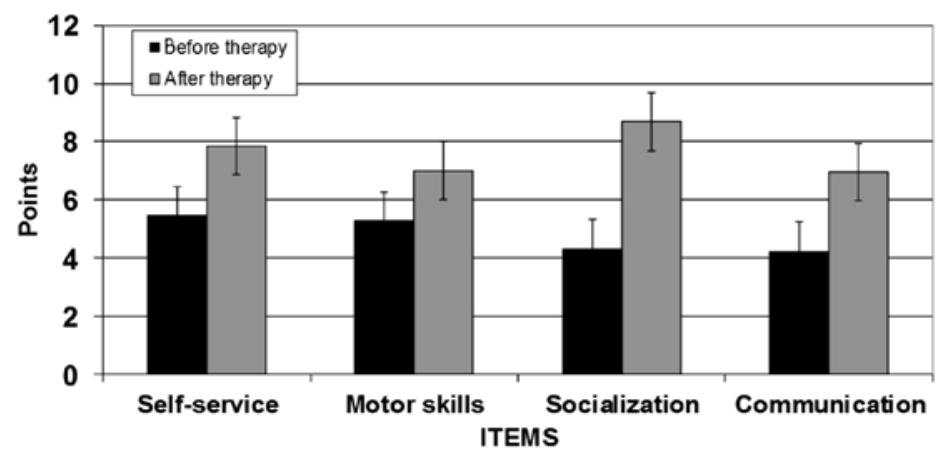

Fig. 3. PAC test Items (score) in riding group before and after the therapy

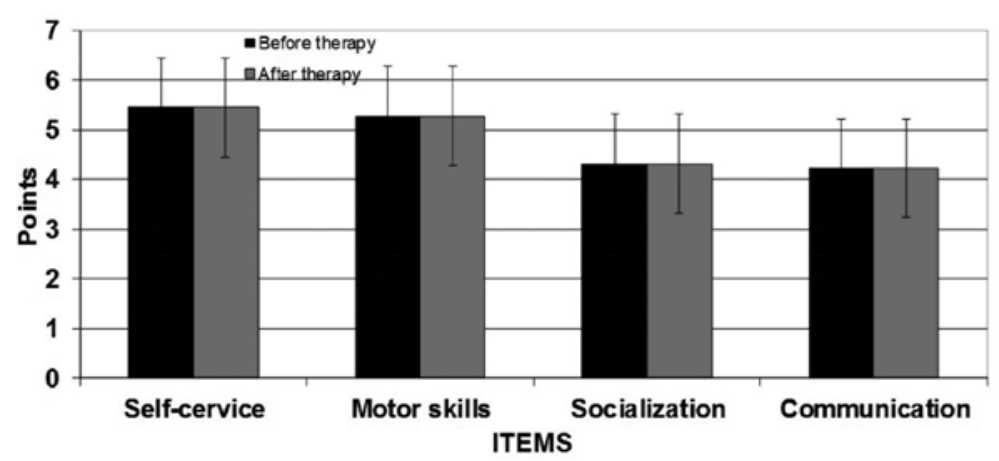

Fig. 4. PAC test Items (score) in non-riding group before and after the therapy 
According to our results horse therapy may be used as an alternative therapy for the children concerned and it may represent a form of rehabilitation in cases when other therapies are not so successful. Most important feature of this study is, that it has a "double-blind" controlled design involving a control group having not received horse therapy but physical therapy. This method validates our data. Our study has implications for the future of children with autism and their parents and therapists who carry out an extremely hard work to improve the skills of the children. Horse therapy may be a good alternative method to help all parties involved in this process.

\section{Acknowledgements}

The research is connected to the scientific program of the "Development of quality-oriented and harmonized $\mathrm{R}+\mathrm{D}+\mathrm{I}$ strategy and functional model at BME" project supported by the New Széchenyi Plan (Project ID: TÁMOP4.2.1/B- 09/1/KMR-2010-0002). This work received support from the National Office for Research and Technology (NKTH), Hungarian National Scientific Research Foundation grant OTKA K-80316 and K-82066, as well as from the Goethe Gait Lab Sponsors (Center Inc., Autodesk Inc., Clementine, Orthotrek, Abexa Inc., 3B Scientific Inc.) and from individuals in the White Horse Foundation.

\section{REFERENCES}

1. Annett M: The theory of an agnostic right shift gene in schizophrenia and autism. Schizophr. Res. 39(3), 177$182(1999)$

2. APAS Manual (www.apas.com) (2005)

3. Asperger H, Frith U (1991): "Autistic Psychopathy in Childhood”. In: Frith U: Autism and Asperger Syndrome, Cambridge University Press, pp. 37-92 ISBN 052138608X

4. Balogh I: Motion Alphabet (Mozgás ABC). ELTE Bárczi Gusztáv Gyógypedagógiai kar (2000)

5. Bozori G (2002): Therapeutic Riding Methods (Lovasterápia - Gondolatok és vázlatok a gyógypedagógiai lovaglás és lovastorna témaköréből). Polu-Press Kkt., Székesfehérvár

6. Bozori G (2005): Results of Therapeutic Rriding (2005) (A gyógypedagógiai lovaglás eredményességének vizsgálata). CSÁK-CODEX Kft., Pákozd

7. Cardinale RC, Shih P, Fishman I, Ford LM, Müller RA: Pervasive rightward asymmetry shifts of functional networks in autism spectrum disorder. JAMA Psychiatry 70(9), 975-982 (2013)

8. Christopher L, Vaughan Brian L, Davis Jeremy C, Connor O (1992): Dynamic of Human Gait Human Kinetics. Publishers Campaign, Illinois

9. Baldwin D (2011): Teaching Orientation and Mobility to Blind Children. The Institute for Innovative Blind Navigation Saginaw, Michigan, 48601

10. Günzburg HC (2000): Pedagogical Analysis and Curriculum (Pedagógiai Analízis és Curriculum a szociális és személyiségfejlődés mérésére értelmi fogyatékosoknál, mely az eljárás négy változatát tartalmazza). ELTE Bárczi Gusztáv Gyógypedagógiai Főiskolai Kar

11. Earl, CJC (1961): Subnormal Personalities: Their Clinical Investigation and Assessment. Baillière, Tindall \& Cox; Baltimore, Williams \& Wilkins, London

12. Györgypál Z (2002): Hippotherapy (Lovasterápia Hippoterápia). Szignatúra Kft., Szombathely

13. GMFM:Gross Motor Measure Function Manual, McMaster University (1993)

14. GPM Anthropological Instruments for Somatology and Osteology. DKSH Switzerland Ltd. (2009)

15. http://hu.wikipedia.org/wiki/T\%C3\%B6megk $\% \mathrm{C} 3 \% \mathrm{~B} 6 \mathrm{z} \% \mathrm{C} 3 \% \mathrm{~A} 9$ ppont

16. http://www.gyogyinfok.hu/szabalykonyv/index.asp?nev=akupunkt $\%$ FAra \&box=bal\&verzio $=114 \&$ mid $=0$

17. http://www.ninds.nih.gov/disorders/autism/detail_autism.htm\#198183082

18. Richards JG (1998): APAS test, PhD thesis, www.apas.com

19. Perry J (1992): Gait Analysis. Slack Incorporated, UK

20. Kiss R (2007): Biomechanics: Study of Motion (Biomechanika - Mozgáselemzés Előadásvázlat gyógytornász és egészségügyi mérnökképzés hallgatóinak). Budapest

21. Kreighbaum, E, Barthels, KM (1996): Biomechanics - A Qualitative Approach for Studying Human Movement. Allyn and Bacon, Needham Heights, MA, USA 
22. Lange N, Dubray MB, Lee JE, Froimowitz MP, Froehlich A, Adluru N, Wright B, Ravichandran C, Fletcher PT, Bigler ED, Alexander AL, Lainhart JE: Atypical diffusion tensor hemispheric asymmetry in autism. Autism Res. 3(6), 350-358 (2010)

23. Stergiou N (2004): Innovative Analyses of Human Movement, Human Kinetics, New York

24. Steiner H, Szilágyi T: Effects of hippotherapy in Down-syndrome (A Hippoterápia hatása a Downszindrómásokra). Rehabilitáció, Budapest (2003)

25. Steiner H, Szilágyi T: Effect of therapeutic riding on the coordination of movements of Down-syndrome children, JCAM 7 No. 1, 59-74 (2006)

26. Szüle E: Therapeutic riding in visually impaired group - Results of AAPAS tests (Lovasterápiában résztvevő látássérült gyermekek APAS mérése és annak eredményei). Előadás, Sarlóspuszta (2006)

27. Wan CY, Marchina S, Norton A, Schlaug G: Atypical hemispheric asymmetry in the arcuate fasciculus of completely nonverbal children with autism. Ann. NY Acad. Sci. 1252, 332-337 (2012) 